Andrew J. Wilson

\title{
The Warning-Assurance Relationship in 1 Corinthians
}

[Das Verhältnis zwischen Warnung und Zusicherung im 1. Korintherbrief.]

Veröffentlicht auf Englisch.

Paulus' erster Brief an die Korinther enthält sowohl emphatische Warnungen als auch bekräftigende Zusicherungen und die

ANDREW J. WILSON

The Warning-Assurance

Relationship

in 1 Corinthians

Beziehung zwischen diesen beiden hat Interpreten oft verwirrt. Zeitweise wirkt es, als würde Paulus die Korinther warnen, ihre eschatologische Erlösung nicht zu verwirken; dann wieder scheint es, als würde er ihnen zusichern, dass dies nicht passieren werde. Versuche, diese Aussagen in Einklang zu bringen, haben oft dazu geführt, die Warnungen, die Zusicherungen oder beide zunichte zu machen.

In dieser aktuellen Analyse aller relevanten Texte zeigt Andrew J. Wilson, dass Paulus' Warnungen und Zusicherungen in einem Spannungsverhältnis stehen und zeigt, dass diese Spannung sowohl schlüssig als auch tatsächlich bewusst von Paulus eingesetzt wird. Debatten zu Beharrlichkeit und Apostasie in Paulus, Gnade und Werk und der Beziehung zwischen göttlicher und menschlicher Vertretung werden diese wichtige Studie berücksichtigen müssen.

Andrew J. Wilson Born 1978; MA from Cambridge, PhD from King's College London; currently serves as Teaching Pastor at King's Church, London.

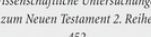

Mohr Siebeck

2017. XII, 223 Seiten. WUNT II 452

ISBN 978-3-16-155467-4

DOI 10.1628/978-3-16-155467-4

eBook PDF $89,00 €$

ISBN 978-3-16-155131-4

fadengeheftete Broschur $89,00 €$
Jetzt bestellen:

https://mohrsiebeck.com/buch/the-warning-assurance-relationship-in-1-corinthians-9783161554674?no_cache=1 order@mohrsiebeck.com

Telefon: +49 (0)7071-923-17

Telefax: +49 (0)7071-51104 